\title{
AUTHOR INDEX FOR VOLUME 96
}

AGARWAL, R. P., MAHMOUD, R. R., O'REGAN, D. and SAKER, S. H.; Some reverse dynamic inequalities on time scales

AIEMSOMBOON, L. and SINTUNAVARAT, W.; A note on the generalised hyperstability of the general linear equation

ALFURAIDAN, M. R. and KHAMSI, M. A.; Fibonacci-Mann iteration for monotone asymptotically nonexpansive mappings

AMENTA, A. and TEUWEN, J.; $L^{p}-L^{q}$ off-diagonal estimates for the OrnsteinUhlenbeck semigroup: some positive and negative results

AN HUEF, A.; see CLARK, L. O.

AXLER, C.; A new upper bound for the sum of divisors function

BRZDĘ, J. and JABŁOŃSKA, E.; On extensions of the generalised Jensen functions on semigroups

CHEN, Q. and ZHAO, G.; A Schwarz lemma for $V$-harmonic maps and their applications

CHEN, X. and LEWIS, M. L.; Itô's theorem and monomial Brauer characters

CHEN, Y.-G.; see LI, Y.-L.

CHEN, Y.-G.; see MA, M.-M.

CHEN, Z.; Dynamics of mathematical models for bioreactors

CLARK, L. O., AN HUEF, A. and LUITEN-APIRANA, P.; Subsets of vertices give Morita equivalences of Leavitt path algebras

CORTES, W. and TAMUSIUNAS, T.; A characterisation for a groupoid Galois extension using partial isomorphisms

DADASHI, V.; Shrinking projection algorithms for the split common null point problem

DANERS, D. and GLÜCK, J.; The role of domination and smoothing conditions in the theory of eventually positive semigroups

DE LIMA, H. F.; see OLIVEIRA, A. M. S.

DELIZIA, C., SHUMYATSKY, P. and TORTORA, A.; On groups with finite conjugacy classes in a verbal subgroup

DING, Y. and LI, J.; Lie $n$-higher derivations and Lie $n$-higher derivable mappings

DOLINKA, I.; Finite regular bands are finitely related - Retraction

DUTRA, E. R. F.; On killers of cable knot groups

EFIMOV, A., GAÁL, M. and RÉVÉSZ, SZ. GY; On integral estimates of nonnegative positive definite functions

EGROT, R.; Closure operators, frames and neatest representations

FERRADA-SALAS, A., HERNÁNDEZ, R. and MARTÍN, M. J.; On convex combinations of convex harmonic mappings

FURTADO, M. F. and ZANATA, H. R.; Multiple solutions for a Kirchhoff equation with nonlinearity having arbitrary growth

GAÁL, M.; see EFIMOV, A. 
GE, M.; see SHI, M. 513

GLÜCK, J.; see DANERS, D. $\quad 286$

GREITHER, C. and ZAÏMI, T.; CM fields without unit-primitive elements $\quad 398$

GUANG, Q.; Self-shrinkers with second fundamental form of constant length 326

GUO, W. and SKIBA, A. N.; On the lattice of $\Pi_{\mathfrak{I}}$-subnormal subgroups of a finite group

GUT, A. and STADTMÜLLER, U.; Complete convergence for arrays and the law of the single logarithm

333

HERNÁNDEZ, R.; see FERRADA-SALAS, A. 256

HOU, J.; see ZENG, Q.

ISLAM, N.; Fluid flow and particle transport through periodic capillaries $\quad 521$

JABŁOŃSKA, E.; see BRZDĘK, J. 110

KHAIRUDDIN, M. A.; Power of posts: a quantitative analysis of Facebook election campaigning interactions

KHAMSI, M. A.; see ALFURAIDAN, M. R. 307

KUMAR, A.; see LUTHRA, P. 274

LEWIS, M. L.; see CHEN, X. 426

LI, J.; see DING, Y. 223

LI, Y.-L. and CHEN, Y.-G.; On additive representation functions 380

LI, Z.; see LIAO, J. $\quad 126$

LIAO, J., ZHANG, X. and LI, Z.; On Littlewood-Paley functions associated $\begin{array}{ll}\text { with the Dunkl operator } & 126\end{array}$

LIU, D. and SUN, X.; Images of higher-order differential operators of $\begin{array}{ll}\text { polynomial algebras } & 205\end{array}$

LIU, H., ZHU, J. and PENG, J.; Two new lower bounds for the spark of a matrix 353

LIU, J.-C.; Congruences for truncated hypergeometric series ${ }_{2} F_{1} \quad 14$

LORANTY, A.; see PAWLAK, R. J. 245

LÜ, F; On algebraic differential equations for the gamma function and $L$-functions in the extended Selberg class 36

LUCA, F.; On polynomials whose roots have rational quotient of differences $\quad 185$

LUITEN-APIRANA, P.; see CLARK, L. O. 212

ŁUKASIK, R.; $K$-spherical functions on abelian semigroups $\quad 479$

LUTHRA, P. and KUMAR, A.; Embeddings and $C^{*}$-envelopes of exact $\begin{array}{ll}\text { operator systems } & 274\end{array}$

MA, M.-M. and CHEN, Y.-G.; Jeśmanowicz' conjecture on Pythagorean triples 30

MAHMOUD, R. R.; see AGARWAL, R. P.

MARTÍN, M. J.; see FERRADA-SALAS, A. 256

MARTÍN-PEINADOR, E., PLICHKO, A. and TARIELADZE, V.; Compatible locally convex topologies on normed spaces: cardinality aspects

MATSUSHITA, S.; On the convergence rate of the Krasnosel'skii-Mann iteration

MUNSCH, M.; On the minimal number of small elements generating finite prime fields 
MUSTAFAYEV, H. S.; Some convergence theorems in Fourier algebras

NOKHODKAR, A.-H.; Symmetric square-central elements in products of orthogonal involutions in characteristic two

OJEDA, I. and VIGNERON-TENORIO, A.; The short resolution of a semigroup algebra

OLIVEIRA, A. M. S. and DE LIMA, H. F.; On the existence of $f$-maximal spacelike hypersurfaces in certain weighted manifolds

OMAR, H. A. M.; Intrusion flow into a density stratified reservoir

O'REGAN, D.; see AGARWAL, R. P.

ÖZBAN, A. Y.; New algebraic-trigonometric inequalities of Laub-Ilani type

PAWELEC, Ł.; Iterated logarithm speed of return times

PAWLAK, R. J. and LORANTY, A.; Stable, almost stable and odd points of dynamical systems

PENG, J.; see LIU, H.

PLICHKO, A.; see MARTÍN-PEINADOR, E.

POLLACK, P. and TROUPE, L.; Two problems concerning irreducible elements in rings of integers of number fields

POULAKIS, D.; A note on Schmidt's conjecture

RAÏSSOULI, M.; Functional versions of some refined and reversed operator mean inequalities

RÉVÉSZ, SZ. GY.; see EFIMOV, A.

RONG, F. and ZHANG, B.; Holomorphic automorphisms and proper holomorphic self-mappings of a type of generalised minimal ball

SAKER, S. H.; see AGARWAL, R. P.

SAMBALE, B.; Regular orbits of coprime linear groups in large characteristic

SANNA, C.; The quotient set of $k$-generalised Fibonacci numbers is dense in $\mathbb{Q}_{p}$

SHI, M., TANG, J., GE, M., SOK, L. and SOLÉ, P.; A special class of quasicyclic codes

SHIMAKURA, M.; Ramification in Kummer extensions arising from algebraic tori

SHUMYATSKY, P.; see DELIZIA, C.

SINTUNAVARAT, W.; see AIEMSOMBOON, L.

SKIBA, A. N.; see GUO, W.

SOK, L.; see SHI, M.

SOLÉ, P.; see SHI, M.

SRIWONGSA, S.; Congruence of symmetric inner products over finite commutative rings of odd characteristic

STADTMÜLLER, U.; see GUT, A.

STANIÓW, B.; On multipliers between some spaces of holomorphic functions

STRBENAC, D.; Novel preprocessing approaches for omics data types and their performance evaluation

SUN, X.; see LIU, D.

TAMUSIUNAS, T.; see CORTES, W. 
TANG, J.; see SHI, M.

TARIELADZE, V.; see MARTÍN-PEINADOR, E. 139

TEUWEN, J.; see AMENTA, A. 154

TORTORA, A.; see DELIZIA, C. 429

TROUPE, L.; see POLLACK, P. 44

VIGNERON-TENORIO, A.; see OJEDA, I. $\quad 400$

WORTHINGTON, J.; Stability theory and Hamiltonian dynamics in the Euler $\begin{array}{ll}\text { ideal fluid equations } & 523\end{array}$

XIAO, Z.; The annihilator of tensor space in the $q$-rook monoid algebra $\quad 77$

YANG, H.; A remark on the stable real forms of complex vector bundles over manifolds

ZAÏMI, T.; see GREITHER, C. $\quad 398$

ZANATA, H. R.; see FURTADO, M. F. 98

ZENG, Q. and HOU, J.; Bipartite subgraphs of $H$-free graphs 1

ZHANG, B.; see RONG, F. $\quad 455$

ZHANG, X.; see LIAO, J. 126

ZHAO, G.; see CHEN, Q. $\quad 504$

ZHU, J.; see LIU, H. 353 


\section{INFORMATION FOR AUTHORS}

The Bulletin of the Australian Mathematical Society aims at quick publication of original research in all branches of mathematics. To ensure speedy publication, only articles which are sufficiently well presented, able to be published without revision, and which are judged by the Editor (often in consultation with an Associate Editor) to be competitive are refereed. This policy is in the interests of authors, as a quick rejection is better than a slow rejection. The Bulletin receives more than five times the material that can be published, therefore there are many commendable papers not accepted. Editorial decisions on acceptance or otherwise are taken quickly, normally within a month of receipt of the paper. Papers are accepted only after peer review.

Manuscripts are accepted for review with the understanding that the same work is not concurrently submitted elsewhere. For a paper to be acceptable for publication, not only should it contain new and interesting results, but also

(i) the exposition should be clear and attractive, and

(ii) the manuscript should be in publishable form, without revision.

Further information regarding these requirements may be found through our website www.austms.org.au/Bulletin. Authors are asked to avoid, as far as possible, the use of mathematical symbols in the title.

Articles should be prepared in $\mathrm{ET}_{\mathrm{E}} \mathrm{X}$ using $\mathcal{A}_{\mathcal{M}} \mathcal{S}$-LTEX packages and submitted as a PDF file via our journal management system, at www.austms.org.au/Publications/Submissions/BAustMS. This permits authors to track their papers through the editorial process. Recent versions of $\mathrm{T}_{\mathrm{E}} \mathrm{X}$ are able to produce PDF files directly. A LTTEX class file for the Bulletin can be downloaded from the website. Authors who need assistance may email the secretary of the Bulletin at editor@bulletin.austms.org.au.

Authors are advised to keep copies of all files of the submitted article; the Bulletin will not accept responsibility for any loss.

\section{EDITORIAL POLICY}

1. References. Arrange references alphabetically (by surname of the first author) and cite them numerically in the text. Ensure the accuracy of the references: authors' names should appear as in the work quoted. Include in the list of references only those works cited, and avoid citing works which are in preparation or submitted. Where the work cited is not readily accessible (for example, a preprint) a copy of the article should be included with your submission.

\section{Abstracts.}

1. Each paper must include an abstract of not more than 150 words, which should contain a brief but informative summary of the contents of the paper, but no inessential details.

2. The abstract should be self-contained, but may refer to the title.

3. Specific references (by number) to a section, proposition, equation or bibliographical item should be avoided.

3. Subject Classification and Key Words. Authors should include a few key words and phrases and one or more classification numbers, following the American Mathematical Society 2010 Mathematics Subject Classification for all codes. Details of this scheme can be found on the web at www.ams.org/msc.

4. Abstracts of PhD Theses. The Bulletin endeavours to publish abstracts of all accepted Australasian $\mathrm{PhD}$ theses in mathematics. One restriction, however, is that the abstract must be received by the Editor within six months of the degree being approved.

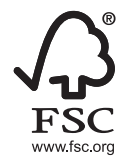

This journal issue has been printed on FSC-certified paper and cover board. FSC is an independent, non-governmental, not-for-profit organisation established to promote the responsible management of the world's forests. Please see www.fsc.org for information. 


\section{Table of Contents}

Two new lower bounds for the spark of a matrix

Liu, H., Zhu, J. \&P Peng, J.

Glosure operators, frames and neatest representations

Egrot, $R$.

A new upper bound for the sum of divisors function

Axler, $C$.

On additive representation functions

Li, Y.-L. \& Chen, Y.-G.

Congruence of symmetric inner products over finite commutative rings of odd characteristic

Sriwongsa, $S$.

CM fields without unit-primitive elements

Greither, C. Ë Zaïmi, T.

The short resolution of a semigroup algebra

Ojeda, I. EV Vigneron-Tenorio, A.

Symmetric square-central elements in products of orthogonal involutions in characteristic two Nokhodkar, A.-H.

Itô's theorem and monomial Brauer characters

Chen, X. \& Lewis, M. L.

On groups with finite conjugacy classes in a verbal subgroup

Delizia, C., Shumyatsky, P. \& Tortora, A.

Regular orbits of coprime linear groups in large characteristic

Sambale, B.

Some reverse dynamic inequalities on time scales

Agarwal, R. P., Mahmoud, R. R., O'Regan, D. E' Saker, S. H.

Holomorphic automorphisms and proper holomorphic self-mappings of a type of generalised minimal ball

Rong, F. \& Zhang, B.

Iterated logarithm speed of return times

Pawelec, $L$.

$K$-spherical functions on abelian semigroups

tukasik, $R$

Some convergence theorems in Fourier algebras

Mustafayer, H.S.

Functional versions of some refined and reversed operator mean inequalities

Raïssouli, $M$.

A Schwarz lemma for $\boldsymbol{V}$-harmonic maps and their applications

Chen, Q. \&̊ Zhao, $G$.

A special class of quasi-cyclic codes

Shi, M., Tang, 7., Ge, M., Sok, L. Ë Solé, P.

Abstracts of PhD Theses

Dynamics of mathematical models for bioreactors

Chen, Z.

Fluid flow and particle transport through periodic capillaries

Islam, $\mathcal{N}$.

Stability theory and Hamiltonian dynamics in the Euler ideal fluid equations

Worthington, $\mathcal{F}$.

Author Index for Volume 96 